\title{
Aflatoxin M1 Contamination in Traditional Yoghurts Produced in Guilan Province, Iran
}

\author{
Mohammad Reza Nikbakht ${ }^{1}$, Shima Lachiniyan'2, Saeid Rahbar ${ }^{3}$, \\ Farhad Oubari' ${ }^{2}$, Zahra Rostami ${ }^{4}$ and Ahmad Tajehmiri ${ }^{2 *}$ \\ 'Department of Pharmacology, Faculty of Medicine, Yasuj University of Medical Sciences, Yasuj, Iran \\ ${ }^{2}$ Medical Biology Research Center, Kermanshah University of Medical Sciences, \\ Kermanshah, Iran; ahmadtajehmiri@kums.ac.ir \\ ${ }^{3}$ Department of Biology, Faculty of Science, Rasht Branch, \\ Islamic Azad University, Rasht, Iran \\ ${ }^{4}$ Department of Microbiology, Faculty of Science, Shahr-e-QodsBranch, \\ Islamic Azad University, Tehran, Iran
}

\begin{abstract}
Aflatoxin M1 is a major carcinogenic compound that may be existed in dairy products. The aim of this study was to determine the occurrence of AFM1 in traditional yoghurt samples in Guilan Province (Northern Iran). Ninety samples of traditional yoghurts were collected during summer and autumn 2014. Enzyme linked Immunosorbentassay (ELISA) which is a rapid and sensitive method was used to determine the presence and levels of AFM1. 100\% of the yoghurt samples were contaminated with 5 and $83 \mathrm{ng} / \mathrm{kg}$ of AFM1. In general, AFM1 in 20 samples (22.22\%) were higher than the maximum tolerance limit ( $50 \mathrm{ng} / \mathrm{kg}$ ) accepted by the European Union. It was therefore concluded that, high occurrence of AFM1 in yoghurt is a serious risk for public health.
\end{abstract}

Keywords: Aflatoxin M1, ELISA Traditional Yoghurt

\section{Introduction}

Aflatoxins are severe toxic secondary metabolite products of some Aspergillus spp. When animals consume feed contaminated with Aflatoxin B1, the toxin is metabolized by liver and is excreted as Aflatoxin M1 via milk. Aflatoxins are toxic compounds, mutagenimmunosuppressive and carcinogen ${ }^{1}$. People in developing countries are at risk ofchronic exposure to aflatoxins through contaminated foods ${ }^{2}$. Among aflatoxins, B1, B2, G1 and G2 are the major toxins. Aflatoxins, M1 and M2 are modified form of AFB1. According to Agency for Research on Cancer (IARC) B1, B2, G1 and G2 as Group 1 carcinogens, and M1 as Group 2. AFM1 display distribution variations according to season, geography and country.
The contamination level of AFM1 is different in hot and cold seasons ${ }^{3}$. The European Union proposes a maximum permissible level of $50 \mathrm{ng} / \mathrm{kg}$ AFM1 in dairy products ${ }^{4}$. When yoghurts are manufactured from AFM1 contaminated milk, the toxin could be detected, because AFM1 is a stable compound that persists against most of food processing stages 5 . Aflatoxins have sub-acute and chronic effects such as chronic hepatitis, liver cancer, jaundice, hepatomegaly in humans ${ }^{3}$. Traditional yoghurts are made in ranches or small dairy shops in Iran. There is little information about the occurrence of AFM1 in Traditional yoghurt in north of $\operatorname{Iran}^{5-7}$. Therefore, the aim of this study was to evaluate the presence of AFM1 in traditional yoghurts produced in Guilan Province (Northern Iran) by ELISA method.

${ }^{*}$ Author for correspondence 


\section{Materials and Methods}

\subsection{Samples}

A total of 90 traditional yoghurt samplesin each season from Guilan Province (Northern Iran) were collected randomly during summer and autumn 2014. The samples were transported to the laboratory and were pasteurized $\left(80^{\circ} \mathrm{C}\right.$ for $\left.3 \mathrm{~min}\right)$. Then, the samples were cooled down to room temperature and diluted in 1:5 in PBS-buffer with pH: 7.2 and $100 \mu$ of this solution was used for ELISA.

\subsection{Determination of AFM1}

AFM1 detection was performed using competitive ELISA using R-Biopharm AFM1 kit. The AFM1 standards and test samples (100 $\mu \mathrm{l}$ per well) in duplicate were added to the wells of a micro-titer plate precoated with antibodies for AFM1 and incubated at room temperature in dark for $60 \mathrm{~min}$. Then added, $100 \mu \mathrm{l}$ of enzyme conjugate was added to the wells and plate was incubated again for 60 min at room temperature in dark. Then $50 \mu$ enzyme substrate (urea peroxide) and chromogen solution (tetramethyl-benzidine) was added to the wells and incubated for $30 \mathrm{~min}$ in dark. At the end, $100 \mu \mathrm{l}$ of stop solution were added to each well. The optical absorbance of each well was read at $450 \mathrm{~nm}$ with ELISA reader ${ }^{3}$. Statistical analysis of results was performed with SPSS 22 software.

\section{Results and Discussion}

The distribution of AFM1 was shown in Table 1. Of the ninety samples analyzed, $100 \%$ samples were found to be contaminated with AFM1. Twenty samples (22.22\%) failed to reach the desired level of the European Union (50ng/ $\mathrm{kg}$ ). The aflatoxin $\mathrm{M}_{1}$ contamination levels were $5-83 \mathrm{ng} / \mathrm{kg}$ with the mean valueof $32.11 \mathrm{ng} / \mathrm{kg}$.

The range of contamination levels varied in two seasons (Table 2). AFM1 in summer ranged from 5-80.5ng/ $\mathrm{kg}$ and in autumn ranged from $5-83 \mathrm{ng} / \mathrm{kg}$ with the mean values 30.7 and $33.53 \mathrm{ng} / \mathrm{kg}$ respectively. The highest

Table 1. Occurrence of AFM1 in traditional yoghurt samples

\begin{tabular}{lccc}
\hline AFM $_{1}$ levelng/kg & No. of samples & $(\%)$ & Range \\
\hline$<25$ & 41 & 45.55 & $5-23.5$ \\
$26-49$ & 29 & 32.22 & $26.5-48$ \\
$\geq 50$ & 20 & 22.22 & $50-83$ \\
Total Samples & 90 & 100 & $5-83$ \\
\hline
\end{tabular}

Table 2. Contamination levels in summer and autumn

\begin{tabular}{lcccc}
\hline Range & Mean & Positive & samples & Season \\
\hline $5-80.5$ & 30.7 & $100 \%$ & 45 & Summer \\
$5-83$ & 33.53 & $100 \%$ & 45 & Autumn \\
\hline
\end{tabular}

mean concentration of aflatoxin M1 registered in autumn $83 \mathrm{ng} / \mathrm{kg}$, while in summer samples highest concentration of aflatoxin $\mathrm{M} 1$ was $80.5 \mathrm{ng} / \mathrm{kg}$.

AFM1 contamination in dairy products is a worldwide problem threatening public health in all areas of the world. The contamination of dairy products with AFM1 display variations according to season, geography and country ${ }^{3}$. Higher level of AFM1 in traditional yoghurt might be due to high level of AFB1 in foodstuff5. Various surveys were performed in order to determine the $\mathrm{AFM}_{1}$ levels in yoghurt. Authors in ${ }^{7}$ reported that all tested traditional yoghurt samples in Guilan province were contaminated with AFM1 $(4.2-78.9 \mathrm{ng} / \mathrm{kg})$ and $13.33 \%$ of the tested samples had contamination levels above the European regulation $(50 \mathrm{ng} / \mathrm{kg})$. According to ${ }^{8}$ in Portugal, stated that ninety six local yoghurt samples tested by HPLC was found, ranging 19-98ng/kg. Authors in ${ }^{5}$ reported $96.25 \%$ of the yoghurt samples (40 industrial, 40 traditional) were contaminated with AFM1 in concentration levels ranging from $<5$ to $91 \mathrm{ng} / \mathrm{kg}$. According to ${ }^{9}$, in Ankara detected AFM1 contamination in $62.88 \%$ yoghurt samples, ranging from $50-800 \mathrm{ng} / \mathrm{kg}$. In another study ${ }^{10}$, in Turkey, 177 yoghurt samples (104 ordinary yoghurt, 21 fruit yoghurtand 52 of strained (Torba) yoghurt) were tested for AFM1 by ELISA method. $11.53 \%$ of ordinary yoghurt, $9.52 \%$ of fruit yoghurt, and $21.15 \%$ of strained yoghurt had higher AFM1 (50ng/kg). Authors in ${ }^{6}$, reported, $100 \%$ pasteurized yoghurt samples and local yoghurt collection from Mazandaran Province (Northern Iran) were positive with concentrations of AFM1 2.1-61.7 and 7-53ng/kg respectively. According to ${ }^{11}$ in Kuwait determined that, in 1 of the 5 yoghurt samples, the presence of AFM1 $(0.03 \mu \mathrm{g} /$ $\mathrm{kg}$ ). Auhtors in ${ }^{12}$ tested AFM1 in yoghurt in South Korea (Seaul) and it was found to be AFM1 detected 84-94\% (ELISA) and 87-93\% (HPLC) respectively. Some study showed that AFM1 concentrations were affected by the seasonal effect. They reported higher level of AFM1 in cold seasons compared to hot seasons. The reason is that in cold seasons milking animals are usually fed with compound feeds and thus concentration of AFB1 increases, which in turn increases AFM1 concentration in milk. So, 
humidity affects the presence of AFB1 in feeds. Aspergillus spp. can easily grow in feedstuffs having humidity between $13 \%$ and $18 \%$, and then they are able to produce aflatoxin in environmental humidity between $50 \%$ and $60 \%$. For this reason, the level of AFM1 in feed in cool months is more than hot months ${ }^{13}$. In the present study, AFM1 was detected in $100 \%$ of the tested yoghurt samples by range from of $5-83 \mathrm{ng} / \mathrm{kg}$. Twenty samples $(22.22 \%)$ had higher AFM1 level than the admissible level $(50 \mathrm{ng} / \mathrm{kg}$ ) established the European Union. AFM1 in summer and autumn samples ranged from 5-80.5 and 5-83ng/kg.

\section{Conclusion}

Mycotoxins, when present at high levels in the diet, cause acute and/or chronic adverse health effects in animals and humans. These compounds may affect many target organs and systems, notably the liver, kidneys, nervous system, endocrine system, immune system, and blood. So, it is essential to have continuous monitoring program over milk and dairy products by governmental food inspection agencies. Beside this, keeping low AFB1 level in feed stuff is of importance.

\section{References}

1. Issazadeh K, Darsanaki RK, Pahlaviani MK. Occurrence of aflatoxin M1 levels in local yogurt samples in Gilan Province, Iran. Ann Biol Res. 2012; 3(8):3853-5.

2. Behfar A, Khorasgani ZN, Alemzadeh Z, Goudarzi M, Ebrahimi R, Tarhani N. Determination of Aflatoxin M1 levels in produced pasteurized milk in Ahvaz City by using HPLC. Jundishapur J Nat Pharm Prod. 2012; 7(2):80-4.

3. Aliabadi MA, Issazadeh $\mathrm{K}$, Darsanaki RK, Rokhi ML, Amini A. Determination of Aflatoxin M1 levels in white cheese samples by ELISA in Gilan Province, Iran. Global Veterinaria. 2012; 8(7):707-10.
4. European Commission (EC). No 1881/2006 of 19 December 2006 setting maximum levels for certain contaminants in foodstuffs. Off J Eur Union. 2006; 364:5-24.

5. Mason S, Arjmandtalab S, Hajimohammadi B, Arsanjani AK, Karami S, Sayadi M, Oryan A. Aflatoxin M1 contamination in industrial and traditional yogurts produced in Iran. Journal of Food Quality and Hazards Control. 2015; 2:11-4.

6. Barjesteh $\mathrm{MH}$, Gholampour I, Noshfar E. Occurrence of Aflatoxin M1 in pasteurized and local yogurt in Mazandaran Province (Northern of Iran) using ELISA. Global Veterinaria. 2010; 4(5):459-62.

7. Tabari M, Tabari K, Tabari O. Aflatoxin M1 determination in yoghurt produced in Guilan province of Iran using immunoaffinity column and high-performance liquid chromatography. Toxicology and Industerial Health. 2012; 29(1):72-6.

8. Martins LM, Martins HM. Aflatoxin M1 in yogurts in Portugal. International Journal of Food Microbiology. 2004; 91(3):315-7.

9. Sarimehmetoglu B, Kuplulu O, Celik TH. Detection of Aflatoxin M1 in cheese samples by ELISA. Food Control. 2004; 15(1):45-9.

10. Akkaya L, Birdane YO, Oguz H, Cemek M. Occurrence of Aflatoxin M1 in yogurt samples from Afyonkarahisar, Turkey. Bull Vet InstPulawy. 2006; 50:517-9.

11. Srivastava VP, Bu-Abbas A, Al-Johar W, Al-Mufti S, Siddiqui MKJ. Aflatoxin M1 contamination in commercial samples of milk and dairy products in Kuwait. Food Addit Contam. 2001; 18(11):993-7.

12. Kim EK, Shon DH, Ryu D, Park JW, Hwang HJ, Kim YB. Occurrence of Aflatoxin M1 in Korean dairy products determined by ELISA and HPLC. Food Additive and Contamination. 2000; 17(1):59-64.

13. Zanjani BR, Rahmani R, Sorkhabadi SMR, Aryan E, Oskouei Z, Sadeghi M, Mood MB. A survey on Aflatoxin M1 in raw milk of Fariman City, Khorasan Province, Iran. Jundishapur J Nat Pharm Prod. 2015; 10(2):1-4. 